\title{
The use of corticosteroids in patients with COPD or asthma does not decrease lung squamous cell carcinoma
}

Zhi-Hong Jian ${ }^{1 \dagger}$, Jing-Yang Huang ${ }^{1 \dagger}$, Frank Cheau-Feng Lin ${ }^{2,3}$, Oswald Ndi Nfor ${ }^{1}$, Kai-Ming Jhang ${ }^{1,4}$, Wen-Yuan Ku ${ }^{1}$, Chien-Chang Ho ${ }^{5}$, Chia-Chi Lung ${ }^{1,6}$, Hui-Hsien Pan ${ }^{2,7}$, Yu-Chiu Liang ${ }^{8}$, Ming-Fang Wu ${ }^{2, *^{*}}$ and Yung-Po Liaw ${ }^{1,6^{*}}$

\begin{abstract}
Background: Asthma and COPD (chronic obstructive pulmonary disease) lead to persistent airway inflammation and are associated with lung cancer. The objective of the study was to assess the relationship between inhaled (ICS) and oral corticosteroid (OCS) use, and risk of lung squamous cell carcinoma (SqCC).

Methods: This study was a nested case-control study. Patients with newly diagnosed asthma or COPD between 2003 and 2010 were identified from the National Health Insurance Database. Cases were defined as patients diagnosed with SqCC after enrollment. For each case, four control individuals who were randomly matched for sex and age and date diagnosis of asthma or COPD were selected.

Results: From the 1,672,455 eligible participants, 793 patients with SqCC were matched with 3,172 controls. The odds ratios (ORs) of SqCC in men who received high and low-dose ICS were 2.18 (95\%Cl, 1.56-3.04) and 1.77 (1.22-2.57), respectively. Similarly, the ORs were $1.46(95 \% \mathrm{Cl}, 1.16-1.84)$ and $1.55(95 \% \mathrm{Cl}, 1.22-1.98)$ for men who were placed on low and high dose OCS. However, there was no significant association between cumulative ICS and/or OCS and risk of SqCC in women. Recent dose increase in corticosteriod was significantly associated with risk of SqCC. Specifically, among men, the ORs for SqCC were $8.08(95 \% \mathrm{Cl}, 3.22-20.30)$ for high-dose ICS + OCS, 4.49 (95\% Cl, 2.05-9.85) for high-dose ICS, and 3.54 (95\% Cl, 2.50-5.01) for high-dose OCS treatments, respectively. The OR for SqCC in women who received high-dose OCS was $6.72(95 \% \mathrm{Cl}$, 2.69-16.81).
\end{abstract}

Conclusion: Corticosteroid use did not decrease SqCC in patients with asthma or COPD. Recent dose increase in corticosteroids was associated with SqCC.

Keywords: Asthma, Chronic obstructive pulmonary disease, Corticosteroids, Lung squamous cell carcinoma

\section{Background}

Squamous cell carcinoma (SqCC) accounts for approximately $20 \%$ of all lung cancers in the United States [1]. It is the predominant histological type of lung cancer in men [2]. Lung cancer has been linked with life expectancy losses in Taiwan [3]. Chronic inflammation and frequent pulmonary exacerbations may result in repeated injury and repair which can lead to a high cell turnover, DNA damage, malignant cell transformation, and ultimately,

\footnotetext{
*Correspondence: mfwu0111@gmail.com; liawyp@csmu.edu.tw

${ }^{+}$Equal contributors

${ }^{2}$ School of Medicine, Chung Shan Medical University, Taichung, Taiwan 'Department of Public Health and Institute of Public Health, Chung Shan Medical University, Taichung, Taiwan

Full list of author information is available at the end of the article
}

development of lung cancer [4]. Asthma and chronic obstructive pulmonary disease (COPD) are chronic airway inflammatory diseases commonly associated with lung cancer $[5,6]$. Severe airflow obstruction is an independent risk factor for lung cancer $[7,8]$. The prevalence of asthma $(11.9 \%)$ and COPD $(2.48 \%)$ in Taiwan is high $[9,10]$.

Oral (OCS) and inhaled corticosteroid (ICS) have reduced local and systemic inflammation among patients with asthma or COPD $[11,12]$. However, studies to assess histologic type of lung cancer among ICS and OCS users are limited. In this study, we investigated the association between corticosteroids and SqCC.

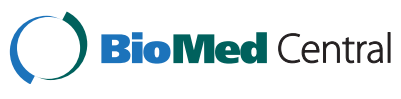

(c) 2016 Jian et al. Open Access This article is distributed under the terms of the Creative Commons Attribution 4.0 International License (http://creativecommons.org/licenses/by/4.0/), which permits unrestricted use, distribution, and reproduction in any medium, provided you give appropriate credit to the original author(s) and the source, provide a link to the Creative Commons license, and indicate if changes were made. The Creative Commons Public Domain Dedication waiver (http://creativecommons.org/publicdomain/zero/1.0/) applies to the data made available in this article, unless otherwise stated. 


\section{Methods}

\section{Data source}

Data used in this study were obtained from 2003 to 2010 using the National Health Insurance Research Database (NHIRD). Taiwan's National Health Insurance covers more than $99 \%$ of the 23 million residents and contains enrollment files, claims data, catastrophic illness files, and registry for treatments. The database is one of the largest datasets described in most epidemiological studies [13-15]. This study used multiple databases: the NHIRD, Taiwan Cancer Registry Database (TCRD), and National Death Registry Database (NDRD) with permission of the Department of Statistics, Ministry of Health and Welfare of Taiwan. The source data was encrypted and the data extracted was anonymous. This study was approved by the Institutional Review Board of the Chung-Shan Medical University Hospital, Taiwan.

\section{Study design}

A nested case-control study was conducted to overcome the time-varying nature of corticosteroid treatment. Analytic data included subjects aged $\geq 20$ years with newly diagnosed asthma or COPD from 2003 to 2010. The date of the first diagnosis of asthma or COPD was defined as the initiation date. Excluded were individuals with incomplete information on sex and registry data. Also excluded were individuals diagnosed with lung cancer before 2002, initiation date, or 2 years after the initiation date.

\section{Identification of patients with lung cancer}

The study began in 2003. Cases with newly diagnosed lung cancer were followed until death, loss to follow-up, or the study end in 2010. Lung cancer was identified using the International Classification of Diseases, Ninth Revision, Clinical Modification (ICD-9-CM) code 162. The index date was defined as the date of first assignment of the above ICD codes.

\section{Case definition}

The TCRD was used to confirm cell types of lung cancer. All major cancer care hospitals in Taiwan are obligated to submit cancer type, initial tumor stages and histology to Taiwan Cancer Registry funded by the Ministry of Health and Welfare [16]. Lung cancer was coded by ICD-9-CM 162 or ICD 10 C34.0, C34.1, C34.2, C34.3, C34.8, and C34.9. Morphological diagnoses were made using the ninth revision of the International Classification of Diseases for Oncology, based on codes 80522, 80523, 80702, 80703, 80713, 80723, 80733, 80743, 80763, 80823, 80833, and 80843 for SqCC.

\section{Control definition}

For each case, up to four control individuals, who were randomly matched for sex, age diagnosed with asthma or COPD, and initiation date were selected without replication from individuals without lung cancer.

The NDRD, NHIRD, and TCRD were used to assess the age at cancer onset, person-year follow-up, death and survival time, and potentially unconfirmed cases diagnosed with cancer.

\section{Inhaled and oral corticosteroid exposure}

We identified patients who were prescribed OCS and ICS between the initiation and index date. Data were collected on prescription dates, prescribed daily dose, and the number of days supplied. In accordance with the Anatomic Therapeutic Chemical classification of ICS drugs, beclomethasone, budesonide, fluticasone, and ciclesonide were selected as the major drugs of interest, whether dispensed alone or in combination with an inhaled $\beta 2$ agonist. The defined daily dose (DDD) recommended by the World Health Organization is a unit for measuring a prescribed amount of drug to standardize the comparison of drug usage between different drugs [17]. All ICS were compared using the following equation: total amount of a drug/DDD of a drug = number of DDDs [18]. Cumulative DDD (cDDD), which encompasses both dosage and duration of exposure, was estimated as the sum of the dispensed DDDs of any ICS and was used to correlate ICS use with SqCC risk.

All OCS prescriptions were converted to hydrocortisone equivalents $(4 \mathrm{mg}$ of hydrocortisone $=1 \mathrm{mg}$ of prednisolone $=5 \mathrm{mg}$ of cortisone $=0.8 \mathrm{mg}$ methylprednisolone $=0.8 \mathrm{mg}$ of triamcinolone $=0.4 \mathrm{mg}$ of paramethasone $=0.15 \mathrm{mg}$ of betamethasone $=0.15 \mathrm{mg}$ of dexamethasone) [19].

An average quarter dose was calculated by dividing the total number of milligrams of OCS or CDDDs of ICS by the number of quarter prescribed during the assessment period.

\section{Covariates}

The diagnoses of pulmonary diseases and comorbidities were confirmed by either 2 outpatient visits or one hospitalization in one year. Baseline pulmonary diseases and other comorbidities are listed as follows: asthma (ICD9-CM: 493), COPD (ICD-9-CM: 490, 491, 492, 494, and 496), pulmonary tuberculosis (ICD-9-CM: 010-012, and 137.0), pneumonia (ICD-9-CM: 486), chronic renal disease (ICD-9-CM: 585 and 586), hyperlipidemia (ICD-9-CM: 272), and smoking-related cancers (ICD-9-CM: 140-150, 157, 160-161, and 189). Type 2 DM (ICD-9-CM: 250, excluding type I DM) is characterized by hyperinsulinemia in the context of insulin resistance and an increased level of circulating insulin-like growth factor 1 which are associated with an increased risk of cancer [20]. Individuals with Type $1 \mathrm{DM}$ were excluded because of exposure to lower levels of exogenously administered insulin. As a proxy of COPD or asthma severity, we assessed the number of outpatient and 
inpatient visits between the initiation and index date. However, information regarding lifestyle or behavior such as smoking was not recorded in the NHIRD, hence preventing direct adjustment of possible confounders.

\section{Statistical analysis}

Data analyses were made using SAS 9.3 software (SAS Institute, Cary, NC). Chi-square and tests were used to compare baseline sociodemographic characteristics and comorbidities between cases and controls. Conditional logistic regression was used to assess the association between corticosteroid use and SqCC. Low or high-dose corticosteroid was defined by the median of corticosteroid dose per quarter. Adjusted odd ratios (ORs) were presented with $95 \%$ confidence intervals (CIs) and a $P$ value of less than 0.05 was considered statistical significance.

\section{Results}

We identified 2,384,046 individuals with first-time diagnosis of asthma or COPD from 2003 to 2010. The total number of individuals excluded were as follows; $<20$ years of age $(n=559,589)$, incomplete data on sex $(n=32,914)$ and registration $(n=104,499)$, type $1 \mathrm{DM}(n=123)$, diagnosed with lung cancer before 2002 or initiation date, and 2 years after the initiation date $(n=14,466)$. The final enrolment included 1,672,455 individuals. A total of 4032 patients were identified with lung cancer, 793 of whom were patients with SqCC.

\section{Patients with SqCC and controls}

The baseline characteristics of patients with SqCC (793) and their controls (3172) are summarized in Table 1. The sample size comprised $87.4 \%$ of men. Cases had comparatively low income, health care utilities, pneumonia, pulmonary tuberculosis, smoking-related cancers, and ICS and OCS use.

\section{ICS and OCS and the risk of developing SqCC}

Compared with non-ICS users (Model 1), the ORs for SqCC in low and high-dose ICS were 2.09 (95\% CI, $1.52-2.88$ ) and 1.88 (95\% CI, 1.32-2.66), respectively (Table 2). Similarly, the ORs for SqCC in low and highdose OCS users were 1.48 (95\% CI, 1.20-1.83) and 1.54 (95\% CI, 1.22-1.93), respectively. Specifically, among men (Model 2), the ORs for SqCC were 2.18 (95\% CI, $1.56-3.04)$ and $1.77(1.22-2.57)$ in low and high-dose ICS, and 1.46 (95\% CI, 1.16-1.84) and 1.55 (95\% CI, 1.22-1.98) in low and high-dose OCS users, respectively. However, there was no increased risk of SqCC among women who received ICS and OCS.

\section{Risk of SqCC in patients with increased dose of corticosteroids}

In Table 3, recent dose increase in corticosteriods within 3 months prior to index date was significantly associated with SqCC (Model 3). The adjusted ORs of SqCC were 8.01 (95\% CI, 3.38-19.01) in high-dose ICS + OCS, 4.14 (95\% CI, 1.98-8.66) in high-dose ICS, and 3.77 (95\% CI, 2.75-5.16) in high-dose OCS users. Specifically, among men (Model 4), the ORs for SqCC were 8.08 (95\% CI, 3.22-20.30) in high-dose ICS + OCS, 4.49 (95 \% CI, 2.059.85) in high-dose ICS, and 3.54 (95\% CI, 2.50-5.01) in high-dose OCS users. Among women (Model 4), the OR for SqCC was 6.72 (95\% CI, 2.69-16.81) in high-dose OCS users. There was no significant interactions between ICS, OCS and SqCC $(P=0.234)$. The interactions between sex and corticosteroids were also not significant $(P=0.764)$.

\section{Discussion}

Over the past decade, some studies have documented a possible link between chronic inflammatory lung diseases and lung cancer $[5,6]$. Corticosteroids are used to control persistent airway inflammation in patients with COPD or asthma. However, the impact of corticosteroids on the specific types of lung cancer has not been addressed. In this study, cumulative doses of OCS and ICS were associated with SqCC in men. Our observation also showed that SqCC was associated with a substantial increase in steroid use in the preceding 3 months. However, it is far too short a time frame to be biologically plausible that steroids are causing the cancer. High-dose steroids are the standard treatment in acute exacerbation of respiratory symptoms that may serve as risk factors for $\mathrm{SqCC}$.

Our results demonstrated that patients with SqCC had significantly higher pneumonia, pulmonary tuberculosis, and smoking-related cancers, but lower hyperlipidemia. Because national databases do not contain detailed information regarding smoking history, occupational exposures, and other risk factors of lung cancer, other diseases (excluding COPD and asthma) may affect the risk of lung SqCC. In a cohort study with $17,859,318$ Taiwanese residents, Jian et al. evaluated gender disparities in pulmonary diseases, comorbidities, and effects on SqCC [5]. A total of 6,637 cases of SqCC (male/female: 5877/760) were identified. Among men, TB and smoking-related cancers were associated with increased risk of SqCC. However, hyperlipidemia was associated with a decreased risk. Among women, TB, low income, type $2 \mathrm{DM}$, and smoking-related cancers were attributed to increased risk of SqCC. In another study involving 22,034 patients with pneumococcal pneumonia, the hazard ratio (HR) of lung cancer was 4.24 (95\% CI, 3.96-4.55) [21]. These results are consistent with our investigations. 
Table 1 Baseline characteristics of controls and cases with lung squamous cell carcinoma

\begin{tabular}{|c|c|c|c|}
\hline & Control $(N=3172)$ & Case $(N=793)$ & $P$-value \\
\hline Sex (\%) & & & 1.000 \\
\hline Men & $2772(87.4)$ & $693(87.4)$ & \\
\hline Women & 400 (12.6) & 100 (12.6) & \\
\hline Low income (\%) & & & 0.028 \\
\hline No & 3133 (98.8) & 775 (97.7) & \\
\hline Yes & $39(1.2)$ & $18(2.3)$ & \\
\hline Urbanization (\%) & & & 0.012 \\
\hline Urban & $1593(50.2)$ & $356(44.9)$ & \\
\hline Suburban & $1082(34.1)$ & $286(36.1)$ & \\
\hline Rural & 497 (15.7) & $151(19.0)$ & \\
\hline $\begin{array}{l}\text { Age diagnosed with } \\
\text { asthma or COPD (year) } \\
\text { (mean } \pm \text { sd) }\end{array}$ & $71.6 \pm 9.4$ & $71.6 \pm 9.4$ & 1.000 \\
\hline $\begin{array}{l}\text { Months between } \\
\text { initiation and index date } \\
(\text { mean } \pm \mathrm{sd})^{\mathrm{a}}\end{array}$ & $46.3 \pm 16.3$ & $46.3 \pm 16.3$ & 1.000 \\
\hline $\begin{array}{l}\text { No. of health care } \\
\text { utilities between } \\
\text { initiation and } \\
\text { index date }\end{array}$ & & & \\
\hline
\end{tabular}

No. of outpatient visits
for asthma (\%)

$\begin{array}{llll}0-10 & 2925(92.2) & 698(88.0) & <0.001 \\ >10 & 247(7.8) & 95(12.0) & \end{array}$

No. of hospitalization for asthma (\%)

$$
\begin{aligned}
& 0-2 \\
& >2
\end{aligned}
$$$$
3128(98.6)
$$$$
44(1.4)
$$$$
777(98.0)
$$$$
16(2.0)
$$

No. of outpatient visits for COPD (\%)

$\begin{array}{lll}0-10 & 2800(88.3) & 622(78.4) \\ >10 & 372(11.7) & 171(21.6)\end{array}$

No. of hospitalization

for COPD (\%)

$\begin{array}{llll}0-2 & 2995(94.4) & 683(86.1) & <0.0001 \\ >2 & 177(5.6) & 110(13.9) & \end{array}$

\begin{tabular}{|c|c|c|c|}
\hline Pneumonia & $1179(37.2)$ & $483(60.9)$ & $<0.0001$ \\
\hline $\begin{array}{l}\text { Pulmonary } \\
\text { tuberculosis }\end{array}$ & $214(6.7)$ & $132(16.7)$ & $<0.0001$ \\
\hline Chronic renal disease & $302(9.5)$ & $90(11.4)$ & 0.123 \\
\hline Diabetes mellitus & 1035 (32.6) & $271(34.2)$ & 0.408 \\
\hline Hyperlipidemia & 999 (31.5) & $213(26.9)$ & 0.011 \\
\hline Smoking-related & $63(2.0)$ & $40(5.0)$ & $<0.0001$ \\
\hline
\end{tabular}

Comorbidities (\%)

cancers
Table 1 Baseline characteristics of controls and cases with lung squamous cell carcinoma (Continued)

Medication within 2-year prior to index date ${ }^{b}$

$\begin{array}{lll}\begin{array}{l}\text { ICS, cDDDs } \\ \text { per quarter }\end{array} & \\ \quad \text { No use } & 2866(90.4) & 607(76.5) \\ \text { Lower dose }(\leqq 18.8) & 156(4.9) & 95(12.0) \\ \text { Higher dose }(>18.8) & 150(4.7) & 91(11.5)\end{array}$

$<0.0001$

OCS (Hydrocortisone equivalent/quarter)

\begin{tabular}{|c|c|c|}
\hline No use & 1955 (61.6) & 338 (42.6) \\
\hline $\begin{array}{l}\text { Lower dose } \\
(\leqq 90.0 \mathrm{mg})\end{array}$ & $644(20.3)$ & 195 (24.6) \\
\hline $\begin{array}{l}\text { Higher dose } \\
\text { (>90.0 mg) }\end{array}$ & $573(18.1)$ & $260(32.8)$ \\
\hline \multicolumn{3}{|l|}{$\begin{array}{l}\text { Aspirin (mg } \\
\text { Der quarter) }\end{array}$} \\
\hline No use & $1998(63.0)$ & 489 (61.7) \\
\hline $\begin{array}{l}\text { Lower dose } \\
(\leqq 3012.5)\end{array}$ & $574(18.1)$ & 165 (20.8) \\
\hline Higher dose & $600(18.9)$ & 139 (17.5) \\
\hline
\end{tabular}

$<0.0001$

$C D D D$ cumulative defined daily dose, $C O P D$ chronic obstructive pulmonary diseases, ICS inhaled corticosteroid, OCS oral corticosteroid, sd standard deviation

anitiation date was defined as the date asthma or COPD was diagnosed while index date was defined as the date lung cancer when diagnosed

${ }^{b}$ Low and high dose medications were defined by the median dose of medications

With effective treatment and control of allergens and irritants, majority of patients with asthma or COPD have a controlled disease though some patients can still be exposed to frequent exacerbations [22, 23]. ICS therapy forms the basis for treatment of asthma and COPD, improving disease control and reducing exacerbations [24-26]. Acute severe exacerbations require the addition of OCS to control increased inflammation and respiratory symptoms [22]. Although corticosteroids are powerful nonspecific antiinflammatory agents, they have little effect on biopsy proven inflammation and did not change the rate of decline of pulmonary function [23]. Airways hyper-responsiveness, remodeling, and inflammation have persisted [27]. This indicates that corticosteroids can't prevent airway inflammation that may lead to lung carcinogenesis.

Few studies on the relationship between corticosteroids and lung cancer have yielded conflicting results. Gundisch et al. found that glucocorticoids promoted tumor cell proliferation in a pre-clinical mouse model of lung carcinoma [28]. Budesonide produced $70 \%$ inhibition of lung tumor multiplicity and $94 \%$ reduction of total tumor in A/J mice [29]. Lee et al. analyzed new adult users of ICS (9177 cases and 37,048 controls) using the Korean national claims database [30]. Their study 
Table 2 Risk of developing squamous cell carcinoma based on the cumulative dose of ICS and OCS

\begin{tabular}{|c|c|c|c|c|c|c|}
\hline & \multicolumn{2}{|l|}{ Mode 1} & \multicolumn{4}{|l|}{ Model 2} \\
\hline & \multicolumn{2}{|l|}{ All } & \multicolumn{2}{|l|}{ Male } & \multicolumn{2}{|l|}{ Female } \\
\hline & OR $(95 \% \mathrm{Cl})$ & $p$-value & OR $(95 \% \mathrm{Cl})$ & $p$-value & OR $(95 \% \mathrm{Cl})$ & $p$-value \\
\hline \multicolumn{7}{|c|}{ Medication within 2-year prior to index date ${ }^{a}$} \\
\hline \multicolumn{7}{|l|}{ ICS (cDDDs per quartier) } \\
\hline No use & 1 & - & 1 & - & 1 & - \\
\hline Lower dose $(\leqq 18.8)^{b}$ & $2.09(1.52-2.88)$ & $<.0001$ & $2.18(1.56-3.04)$ & $<.0001$ & $1.16(0.35-3.85)$ & 0.812 \\
\hline Higher dose (>18.8) & $\mathbf{1 . 8 8}(1.32-2.66)$ & $<0.001$ & $1.77(1.22-2.57)$ & 0.003 & $2.96(0.87-10.04)$ & 0.082 \\
\hline \multicolumn{7}{|c|}{ OCS (Hydrocortisone equivalent/quarter) } \\
\hline No use & 1 & - & 1 & - & 1 & - \\
\hline Lower dose $(\leqq 90.0 \mathrm{mg})^{\mathrm{b}}$ & $1.48(1.20-1.83)$ & $<0.001$ & $1.46(1.16-1.84)$ & 0.001 & $1.59(0.88-2.87)$ & 0.124 \\
\hline Higher dose (>90.0 mg) & $\mathbf{1 . 5 4}(1.22-1.93)$ & $<0.001$ & $1.55(1.22-1.98)$ & $<0.001$ & $1.51(0.75-3.04)$ & 0.253 \\
\hline
\end{tabular}

Each model was adjusted by low income, urbanization, health care utility, comorbidities and aspirin use

$C D D D$ cumulative defined daily dose, $C I$ confidence interval, ICS inhaled corticosteroid, OCS oral corticosteroid, OR odds ratio

andex date was defined as the date of lung cancer diagnosis

${ }^{\mathrm{b}}$ Low and high-dose ICS and OCS were defined by the median of cumulative ICS and OCS dose (18.8 DDD / quarter and $90 \mathrm{mg}$

hydrocortisone/quarter, respectively).

Significant data are presented in bold font

findings showed that ICS use had a significant linear association with a decreased lung cancer incidence. The adjusted OR was 0.79 (95\% CI, 0.69-0.90). In a study involving 10,474. United State veterans with COPD and a median follow-up of 3.8 years, a dose-dependent decreased risk of lung cancer was associated with ICS (triamcinolone >1,200 ug/day: adjusted HR, 0.39; $95 \% \mathrm{CI}$, 0.16-0.96) [31]. However, after excluding participants who were diagnosed with lung cancer in the first year after enrollment, there was no significant reduction in lung cancer. In a nested case-control study involving patients (127 cases and 1470 controls) with newly diagnosed COPD who quitted smoking, and regular use of ICS and bronchodilators, the HRs for lung cancer were 0.50 (95\% CI, 0.27-0.90) in ICS + long acting beta agonist users and 0.64 (0.42-0.98) in ICS users compared with short-acting bronchodilators users [32].
However, none of these trials has evaluated the relationship between corticosteroids and specific types of lung cancer. Asthma and COPD have been closely associated with $\mathrm{SqCC}$ [5]. In this study, a recent dose increase in ICS and OCS is associated with SqCC. It is possible that lung cancer may be found after exacerbation of respiratory symptoms or treatment failure. An increased lung cancer risk was strongest 2 years after asthma was diagnosed [33]. Lung cancer is hard to diagnose. Prior to referral, a third of patients consulted their general practitioners three or more times with health problems related to lung cancer [34]. Diagnosis may be initially delayed because of symptomatic masks resulting from exacerbations of COPD and respiratory comorbidities [35, 36]. Prognosis of lung cancer is very poor. Longer diagnostic intervals have been associated with increased cancer stage and mortality [37]. In the presence of continuing or

Table 3 Adjusted risk for squamous cell carcinoma in patients with recent dose-increase in corticosteroids

\begin{tabular}{|c|c|c|c|c|c|c|}
\hline \multicolumn{2}{|c|}{ Months before index date ${ }^{a}$} & \multirow{2}{*}{\multicolumn{3}{|c|}{ Model 3}} & \multicolumn{2}{|l|}{ Model 4} \\
\hline \multirow[t]{2}{*}{$-6--3$} & \multirow[t]{2}{*}{$-3-0$} & & & & \multirow{2}{*}{$\begin{array}{l}\text { Men } \\
\text { OR (95 \% Cl) }\end{array}$} & \multirow{2}{*}{$\begin{array}{l}\text { Women } \\
\text { OR (95 \% Cl) }\end{array}$} \\
\hline & & Control & Case & OR $(95 \%$ Cl) & & \\
\hline \multicolumn{7}{|l|}{$\mathrm{SqCC}$} \\
\hline$I C S_{L}+O C S_{L}$ & $I C S_{L}+O C S_{L}$ & 2589 & 475 & 1 & 1 & 1 \\
\hline $\mathrm{ICS} \mathrm{L}_{\mathrm{L}}+\mathrm{OCS} \mathrm{S}_{\mathrm{L}}$ & $\mathrm{ICS}_{\mathrm{L}}+\mathrm{OCS} \mathrm{S}_{\mathrm{H}}$ & 145 & 107 & $3.77(2.75-5.16)$ & $3.54(2.50-5.01)$ & $6.72(2.69-16.81)$ \\
\hline $\mathrm{ICS}_{\mathrm{L}}+\mathrm{OCS}_{\mathrm{L}}$ & $I C S_{H}+O C S_{L}$ & 20 & 18 & $4.14(1.98-8.66)$ & $4.49(2.05-9.85)$ & $3.65(0.26-51.94)$ \\
\hline $\mathrm{ICS}_{\mathrm{L}}+\mathrm{OCS}_{\mathrm{L}}$ & $\mathrm{ICS}_{\mathrm{H}}+\mathrm{OCS}_{\mathrm{H}}$ & 14 & 22 & $8.01(3.38-19.01)$ & $8.08(3.22-20.30)$ & $3.77(0.24-60.39)$ \\
\hline
\end{tabular}

$P$ for ICS $\times$ OCS interaction $=0.234$

Each model was adjusted for low income, urbanization, health care utility, comorbidities, and aspirin use

Low and high-dose ICS and OCS were defined by the median of cumulative ICS and OCS dose (18.8 DDD/quarter and 90 mg hydrocortisone/quarter, respectively) $\mathrm{Cl}$ confidence interval, ICS inhaled corticosteroid, ICS $\mathrm{H}$ high cumulative dose of inhaled corticosteroid, ICS low cumulative dose of inhaled corticosteroid, OCS oral corticosteroid, $O C S_{H}$ high cumulative dose of oral corticosteroid, $O C S_{L}$ low cumulative dose of oral corticosteroid, OR odds ratio ${ }^{a}$ Index date was defined as the date of lung cancer diagnosis Significant data are presented in bold font 
changing respiratory symptoms, doctors should be aware of the symptoms associated with lung cancer.

Our study results indicated no association between $\mathrm{cu}-$ mulative dose of corticosteroids and SqCC in women. In Taiwan, smoking is almost ten times more prevalent in men (45.7 \%) than women (4.8 \%) [38]. This might have influenced the observed differences in risk of developing $\mathrm{SqCC}$ between men and women. Except cigarette smoking, cooking fumes had been associated with female SqCC [39]. Sex hormones play a role in gender-based differences such as incidence, risk, histology, and pathogenesis of lung diseases, and may either contribute to pathogenesis of disease or serve as protective factors [40]. Besides, there were insufficient number of female patients to accurately analyze. More studies ought to be conducted to investigate the association between corticosteroids and SqCC among women.

This study has several strengths. First, the sample size is large with a long follow-up. It was based on nationwide databases, hence selection bias was possibly minimized. Second, to enhance the reliability of temporal relationship between corticosteroid use and $\mathrm{SqCC}$, we excluded individuals who were diagnosed with lung cancer before 2002 and initiation date, or 2 years after initiation date. Nevertheless, this study had some limitations. First, corticosteroid exposure was assessed solely by refills recorded in the NHIRD, not by whether the subjects actually used their medication. Second, NHIRD, NDRD, and TCRD do not contain detailed information regarding smoking history, radon exposure, occupational exposures, diet preference, and family history, all of which may be risk factors for lung cancer.

\section{Conclusions}

The use of corticosteroids in patients with asthma and COPD was associated with lung SqCC, especially in men. Recent dose-increase in corticosteroids was associated with SqCC. Lung cancer screening is necessary when treatment goals for asthma or COPD are not being met or when patients are not responding to current therapy.

\begin{abstract}
Abbreviation
CDDD: Cumulative defined daily dose; Cl: Confidence interval; COPD: Chronic obstructive pulmonary disease; DDD: Defined daily dose; DM: Diabetes mellitus; HR: Hazard ratio; ICD-9-CM: International Classification of Diseases, Ninth Revision, Clinical Modification code; ICS: Inhaled corticosteroid; NDRD: National Death Registry Database; NHIRD: National Health Insurance Research Database; OCS: Oral corticosteroid; OR: Odds ratio; SqCC: Lung squamous cell carcinoma; TCRD: Taiwan Cancer Registry Database.
\end{abstract}

\section{Competing interests}

The authors declare that they have no competing interests.

\section{Authors' contributions}

$\mathrm{ZHJ}, \mathrm{YPL}$, and MFW conceived and designed the study. JYH, CCH, and $\mathrm{CCL}$ performed the experiments. $\mathrm{ZHJ}, \mathrm{JYH}, \mathrm{CCH}$, and HHP analyzed the data. JYH and $C C L$ contributed analysis tools. ONN, FCFL, WYK, KMJ, and YCL provided critical inputs on design, analysis, and interpretation of the study. $\mathrm{ZHJ}$ and JYH drafted the initial manuscript. All the authors had access to the data. All authors read and approved the final manuscript as submitted.

\section{Acknowledgements}

This study was jointly supported by Grants (NSC 102-2119-M-040 -001) from the National Science Council and MOST 103-2119-M-040 -001 from the Ministry of Science and Technology. The authors acknowledge the Department of Statistics, Ministry of Health and Welfare of Taiwan for providing the NHIRD, TCRD, and NDRD. The descriptions or conclusions herein do not represent the viewpoint of the Bureau.

\section{Author details}

${ }^{1}$ Department of Public Health and Institute of Public Health, Chung Shan Medical University, Taichung, Taiwan. ${ }^{2}$ School of Medicine, Chung Shan Medical University, Taichung, Taiwan. ${ }^{3}$ Department of Thoracic Surgery, Chung Shan Medical University Hospital, Taichung, Taiwan. ${ }^{4}$ Department of Neurology, Changhua Christian Hospital, Changhua, Taiwan. ${ }^{5}$ Department of Physical Education, Fu Jen Catholic University, New Taipei City, Taiwan. ${ }^{6}$ Department of Family and Community Medicine, Chung Shan Medical University Hospital, No. 110, Sec. 1 Jianguo N. Rd., Taichung City 40201, Taiwan. 'Department of Pediatrics, Chung Shan Medical University Hospital, Taichung, Taiwan. ${ }^{8}$ College of Humanities and Social Sciences, Taipei Medical University, Taipei City, Taiwan. ${ }^{9}$ Divisions of Medical Oncology and Pulmonary Medicine, Chung Shan Medical University Hospital, Taichung, Taiwan.

Received: 3 June 2015 Accepted: 25 November 2015

Published online: 03 December 2015

\section{References}

1. Travis WD. Pathology of lung cancer. Clin Chest Med. 2011;32:669-92.

2. Sereno M, Esteban IR, Zambrana F, Merino M, Gomez-Raposo C, LopezGomez M, et al. Squamous-cell carcinoma of the lungs: is it really so different? Crit Rev Oncol Hematol. 2012;84:327-39.

3. Hung MC, Lai WW, Chen HH, Su WC, Wang JD. Comparison of expected health impacts for major cancers: Integration of incidence rate and loss of quality-adjusted life expectancy. Cancer Epidemiol. 2015;39:126-32.

4. Gomes M, Teixeira AL, Coelho A, Araujo A, Medeiros R. The role of inflammation in lung cancer. Adv Exp Med Biol. 2014;816:1-23.

5. Jian ZH, Lung CC, Huang JY, Ko PC, Jan SR, Ndi Nfor O, et al. The coexistence of common pulmonary diseases on the Histologic type of lung cancer in both genders in Taiwan: A STROBE-compliant article. Medicine. 2014;93:e127.

6. Ballaz S, Mulshine JL. The potential contributions of chronic inflammation to lung carcinogenesis. Clin Lung Cancer. 2003;5:46-62.

7. Maldonado F, Bartholmai BJ, Swensen SJ, Midthun DE, Decker PA, Jett JR. Are airflow obstruction and radiographic evidence of emphysema risk factors for lung cancer? A nested case-control study using quantitative emphysema analysis. Chest. 2010;138:1295-302.

8. Mannino DM, Aguayo SM, Petty TL, Redd SC. Low lung function and incident lung cancer in the united states: data from the first national health and nutrition examination survey follow-up. Arch Intern Med. 2003;163:1475-80

9. Hwang CY, Chen YJ, Lin MW, Chen TJ, Chu SY, Chen CC, et al. Prevalence of atopic dermatitis, allergic rhinitis and asthma in Taiwan: a national study 2000 to 2007. Acta Derm Venereol. 2010;90:589-94.

10. Wang YC, Lin JM, Li CY, Lee LT, Guo YL, Sung FC. Prevalence and risks of chronic airway obstruction: a population cohort study in taiwan. Chest. 2007;131:705-10

11. Hattotuwa KL, Gizycki MJ, Ansari TW, Jeffery PK, Barnes NC. The effects of inhaled fluticasone on airway inflammation in chronic obstructive pulmonary disease: a double-blind, placebo-controlled biopsy study. Am J Respir Crit Care Med. 2002;165:1592-6.

12. Bentley AM, Hamid Q, Robinson DS, Schotman E, Meng Q, Assoufi B, et al. Prednisolone treatment in asthma. Reduction in the numbers of eosinophils, $T$ cells, tryptase-only positive mast cells, and modulation of IL-4, IL-5, and interferon-gamma cytokine gene expression within the bronchial mucosa. Am J Respir Crit Care Med. 1996;153:551-6.

13. Pan $\mathrm{HH}$, Chen $\mathrm{CT}$, Sun HL, Ku MS, Liao PF, Lu KH, et al. Comparison of the effects of air pollution on outpatient and inpatient visits for asthma: a population-based study in Taiwan. PLoS One. 2014;9:e96190.

14. Jian ZH, Huang JY, Ko PC, Jan SR, Nfor ON, Lung CC, et al. Impact of coexisting pulmonary diseases on survival of patients with lung adenocarcinoma: a STROBE-compliant article. Medicine. 2015;94:e443. 
15. Huang JY, Jian ZH, Nfor ON, Ku WY, Ko PC, Lung CC, et al. The effects of pulmonary diseases on histologic types of lung cancer in both sexes: a population-based study in Taiwan. BMC Cancer. 2015;15:834.

16. Chiang CJ, You SL, Chen CJ, Yang YW, Lo WC, Lai MS. Quality assessment and improvement of nationwide cancer registration system in Taiwan: a review. Jpn J Clin Oncol. 2015;45:291-6.

17. Vlahovic-Palcevski V, Gantumur M, Radosevic N, Palcevski G, Vander SR. Coping with changes in the Defined Daily Dose in a longitudinal drug consumption database. Pharm World Sci. 2010;32:125-9.

18. World Health Oragnization. WHO Collaborating Centre for Drugs Statistics Methodology: ATC/DDD Index 2015. http://www.whocc.no/atc_ddd_index/ (2015). Accessed 24 Apr 2015.

19. Jick SS, Lieberman ES, Rahman MU, Choi HK. Glucocorticoid use, other associated factors, and the risk of tuberculosis. Arthritis Rheum. 2006;55:19-26.

20. Szablewski L. Diabetes mellitus: influences on cancer risk. Diabetes Metab Res Rev. 2014;30:543-53.

21. Lin TY, Huang WY, Lin JC, Lin CL, Sung FC, Kao CH, et al. Increased lung cancer risk among patients with pneumococcal pneumonia: a nationwide population-based cohort study. Lung. 2014;192:159-65.

22. Williams SG, Schmidt DK, Redd SC, Storms W. Key clinical activities for quality asthma care. Recommendations of the National Asthma Education and Prevention Program. MMWR Recomm Rep. 2003;52(Rr-6):1-8.

23. Calverley PM. The role of corticosteroids in chronic obstructive pulmonary disease. Semin Respir Crit Care Med. 2005;26:235-45.

24. Chung KF, Caramori G, Adcock IM. Inhaled corticosteroids as combination therapy with beta-adrenergic agonists in airways disease: present and future. Eur J Clin Pharmacol. 2009:65:853-71.

25. Singh D, Nicolini G, Bindi E, Corradi M, Guastalla D, Kampschulte J, et al. Extrafine beclomethasone/formoterol compared to fluticasone/salmeterol combination therapy in COPD. BMC Pulm Med. 2014;14:43.

26. Zhong $N$, Lin J, Mehta P, Ngamjanyaporn P, Wu TC, Yunus F. Real-life effectiveness of budesonide/formoterol maintenance and reliever therapy in asthma patients across Asia: SMARTASIA study. BMC Pulm Med. 2013;13:22.

27. Lazaar AL, Panettieri Jr RA. Is airway remodeling clinically relevant in asthma? Am J Med. 2003;115:652-9.

28. Gundisch S, Boeckeler E, Behrends U, Amtmann E, Ehrhardt H, Jeremias I. Glucocorticoids augment survival and proliferation of tumor cells. Anticancer Res. 2012;32:4251-61.

29. Yao R, Wang Y, Lemon WJ, Lubet RA, You M. Budesonide exerts its chemopreventive efficacy during mouse lung tumorigenesis by modulating gene expressions. Oncogene. 2004;23:7746-52.

30. Lee CH, Hyun MK, Jang EJ, Lee NR, Kim K, Yim JJ. Inhaled corticosteroid use and risks of lung cancer and laryngeal cancer. Respir Med. 2013;107:1222-33.

31. Parimon T, Chien JW, Bryson CL, McDonell MB, Udris EM, Au DH. Inhaled corticosteroids and risk of lung cancer among patients with chronic obstructive pulmonary disease. Am J Respir Crit Care Med. 2007;175:712-9.

32. Kiri VA, Fabbri LM, Davis KJ, Soriano JB. Inhaled corticosteroids and risk of lung cancer among COPD patients who quit smoking. Respir Med. 2009:103:85-90.

33. Rosenberger A, Bickeboller H, McCormack V, Brenner DR, Duell EJ, Tjonneland A, et al. Asthma and lung cancer risk: a systematic investigation by the International Lung Cancer Consortium. Carcinogenesis. 2012;33:587-97.

34. Lyratzopoulos G, Abel GA, McPhail S, Neal RD, Rubin GP. Measures of promptness of cancer diagnosis in primary care: secondary analysis of national audit data on patients with 18 common and rarer cancers. Br J Cancer. 2013;108:686-90.

35. Mitchell ED, Rubin G, Macleod U. Understanding diagnosis of lung cancer in primary care: qualitative synthesis of significant event audit reports. $\mathrm{Br} J \mathrm{Gen}$ Pract. 2013:63:e37-46.

36. Neal RD, Robbe IJ, Lewis M, Williamson I, Hanson J. The complexity and difficulty of diagnosing lung cancer: findings from a national primary-care study in Wales. Prim Health Care Res Dev. 2015;16:436-49.

37. Torring ML, Frydenberg M, Hansen RP, Olesen F, Vedsted P. Evidence of increasing mortality with longer diagnostic intervals for five common cancers: a cohort study in primary care. Eur J Cancer. 2013;49:2187-98.

38. Tsai YW, Tsai TI, Yang CL, Kuo KN. Gender differences in smoking behaviors in an Asian population. J Womens Health. 2008;17:971-8.

39. Le CH, Ko YC, Cheng LS, Lin YC, Lin HJ, Huang MS, et al. The heterogeneity in risk factors of lung cancer and the difference of histologic distribution between genders in Taiwan. Cancer Causes Control. 2001;12:289-300.

40. Caracta CF. Gender differences in pulmonary disease. Mt Sinai J Med. 2003;70:215-24.

\section{Submit your next manuscript to BioMed Central and we will help you at every step:}

- We accept pre-submission inquiries

- Our selector tool helps you to find the most relevant journal

- We provide round the clock customer support

- Convenient online submission

- Thorough peer review

- Inclusion in PubMed and all major indexing services

- Maximum visibility for your research

Submit your manuscript at www.biomedcentral.com/submit 